\title{
Reliability of the automatic procedures for locating earthquakes in southwestern Alps and northern Apennines (Italy)
}

\author{
Chiara Turino • Paola Morasca • \\ Gabriele Ferretti • Davide Scafidi . \\ Daniele Spallarossa
}

Received: 17 June 2008 / Accepted: 14 May 2009 / Published online: 4 June 2009

(C) Springer Science + Business Media B.V. 2009

\begin{abstract}
Reliable automatic procedure for locating earthquake in quasi-real time is strongly needed for seismic warning system, earthquake preparedness, and producing shaking maps. The reliability of an automatic location algorithm is influenced by several factors such as errors in picking seismic phases, network geometry, and velocity model uncertainties. The main purpose of this work is to investigate the performances of different automatic procedures to choose the most suitable one to be applied for the quasi-real-time earthquake locations in northwestern Italy. The reliability of two automatic-picking algorithms (one based on the Characteristic Function (CF) analysis, CF picker, and the other one based on the Akaike Information Criterion (AIC), AIC picker) and two location methods ("Hypoellipse" and "NonLinLoc" codes) is analysed by comparing the automatically determined hypocentral coordinates with reference ones. Reference locations are computed by the "Hypoellipse" code considering manually revised data and tested using quarry blasts. The comparison is made on a
\end{abstract}

C. Turino · P. Morasca · G. Ferretti $(\bowtie)$.

D. Scafidi · D. Spallarossa

Dip.Te.Ris., University of Genova,

Viale Benedetto XV 5, 16132, Genova, Italy

e-mail: ferretti@dipteris.unige.it dataset composed by 575 seismic events for the period 2000-2007 as recorded by the Regional Seismic network of Northwestern Italy. For $\mathrm{P}$ phases, similar results, in terms of both amount of detected picks and magnitude of travel time differences with respect to manual picks, are obtained applying the AIC and the CF picker; on the contrary, for S phases, the AIC picker seems to provide a significant greater number of readings than the CF picker. Furthermore, the "NonLinLoc" software (applied to a 3D velocity model) is proved to be more reliable than the "Hypoellipse" code (applied to layered 1D velocity models), leading to more reliable automatic locations also when outliers (wrong picks) are present.

Keywords Automatic picker - Automatic earthquake location method - Akaike Information Criterion - Characteristic Function • Southwestern Alps • Northern Apennines

\section{Introduction}

The advent of digital recording systems and fast transmission channels makes real-time earthquake monitoring possible and strongly encourages the development of accurate and reliable seismic warning procedures. The automatic, interactive, and quasi-real-time analysis of seismic data for detecting onset picking and identifying signal 
phases in seismograms represents an important activity for the organizations that manage regional and local seismic networks. Using automatic picking algorithms, epicenters/hypocenters, and magnitudes are automatically computed within a few tens of seconds after the occurrence of an earthquake. Preliminary estimates of location parameters are generally sent to scientific and civil organization as alert messages and/or shaking maps for monitoring and surveillance purposes.

The reliability of any automatic location algorithm is strongly dependent on the reliability of the phase picker and on the adopted location method. Conventionally, robust automatic phase picking leads to the identification of as many as possible number of accurate and reliable $\mathrm{P}$-phase readings and $\mathrm{S}$-phase readings (the latter one mainly if there is the availability of seismic signals recorded by three-component stations), avoiding false or imprecise picks. A location method applied to automatic picks, on the other hand, has to lead to reliable hypocentral parameters even if (a) the number of available data is limited (e.g., $6<$ phase number $<10$ ) and/or a good geographic range of picked stations is lacking (e.g., azimuthal gap $>180^{\circ}$ ), (b) the seismic phase database is corrupted by one or more wrong readings (outliers), and (c) S phases are lacking.

There are many published studies that deal with automatic phase-detection algorithms (e.g., Allen 1982; Chiaruttini 1991; Fletcher et al. 1992; Tarvainen 1992; Ruud and Husebye 1993; Ruud et al. 1993; Earle and Shearer 1994; Evans and Pitt 1995; Tong 1995; Tong and Kennett 1996; Wagner and Owens 1996; Dai and MacBeth 1995; Patanè and Ferrari 1999; Sleeman and van Eck 1999) and that examine the efficiency of location methods related to the quality of the phase readings and of other factors such as the network geometry, the number of available phases, and the knowledge of the crustal structure (e.g., Pavlis 1986; Gomberg et al. 1990; Billings et al. 1994; Pujol 1996; Lienert 1997; Rong-Song 1999).

In this paper, we compare two different picking algorithms and two different location methods by analyzing their performances when applied as automatic procedures to an actual dataset of more than 500 seismic events recorded by the Regional Seismic network of Northwestern Italy (RSNI; www.dipteris.unige.it/geofisica) in the area of the southwestern Alps and northern Apennines. In particular, we investigate the Characteristic Function (CF)-based picker (Allen 1978, 1982) and the Akaike Information Criterion (AIC)-based picker (Akaike 1974; Sleeman and van Eck 1999). Then, starting from automatic readings, two location procedures are compared: the first based on Geiger's method (Geiger 1912; Hypoellipse code, Lahr 1979) and the second based on a probabilistic nonlinear global search approach (NonLinLoc method, Lomax et al. 2000; Lomax and Curtis 2001).

Note that the CF picker has been chosen since Allen's picking system is still part of several and widespread tools used by the seismic community for seismic signal processing and analysis, such as Earthworm (Johnson et al. 1994) and Sac2000 (Goldstein et al. 1999, 2003). On the other hand, the AIC picker has been already shown, as described by Sleeman and van Eck (1999), to provide accurate and robust automatic picks on large experimental database, and mainly, it is based on the application of the AIC that completely differs from short-term average long-term average (STA/LTA) detector-based algorithms.

The main purpose of this work is the evaluation of the reliability of each automatic algorithm by comparing outcomes (picks and hypocentral coordinates) with reference one (derived from manually revised data) and therefore the selection of the most suitable automatic location procedure for quasi-real-time processing of seismic data recorded in the northwestern Italy by the RSNI network. The selection is performed by choosing the most reliable picking algorithm and the most appropriate location method that lead to locations as much as possible similar to the reference ones and to the smallest number of events with location differences greater than $10 \mathrm{~km}$ with respect to the reference data.

\section{Event detection processing overview}

In the last years, the RSNI network greatly improved its performances with the complete renewal of the seismic stations (in terms of instruments and transmission systems) that are now 
fully digital and "in real time". Today, the network consists of 30 broadband seismic stations with high dynamic digitizers $(>120 \mathrm{Db})$ and with real-time dedicated large-band links to the processing center of the University of Genoa. Since the purpose of this study focuses on the selection of the more appropriate phase picker and location method for "quasi-real-time" earthquake locating through the RSNI network, the approach for performing event detection is here briefly described (we refer the reader to Ferretti et al. (2008) for a more in-depth description of the all-comprehensive processing procedures).

The event detection algorithm, based on the NaqsServer data acquisition system (developed by the Nanometrics Inc., www.nanometrics.ca), is applied to the continuous stream of real-time waveforms transmitted by the RSNI stations in order to extract from the data buffer 240-s-long time window containing possible seismic event. Such procedure is based on a STA/LTA analysis (empirically calibrated for each station as a function of site's ambient noise, sensor type, etc.) and on a coincident system (empirically calibrated for RSNI network) defining the number of data channels (hereinafter TrigsToStart number) which must be triggering coincidentally within a coincident window in order to declare the start of a potential event. At present, in the area monitored by the RSNI network, the magnitude threshold for both earthquakes and explosions is proved to be less than 1.0 local magnitude. This is derived from a comparison among other seismic bulletins (published for area including the northwestern Italy, such as Istituto Nazionale di Geofisica e Vulcanologia (INGV), Eldgenossiche Technische Hochschule Zurich (ETH), and European Mediterranean Seismological Centre bulletin), and from several tests performed by considering alternative parameters for the eventdetection algorithm. The parameters selected and adopted at present lead to the best compromise between the lowest magnitude of a detectable event and the smallest amount of "false" events (that are ambient or anthropic noise coincidentally triggered by a number of data channels greater than the TrigsToStart number).

Although it is not the aim of this work, the automatic location algorithms, described and tested in the following paragraphs, are proved to be robust leading to the recognition of "false" events by means an additional algorithm based on the evaluation of the quality of the location: "false" events are proved to be not locatable (e.g., insufficient number of readings) or locatable with a small number of phases or with high location errors (horizontal error, vertical error, residual root mean square (RMS), etc.). Nevertheless, in this paper, we focus our attention to the selection of the best location procedure that leads to the most reliable locations considering "true" seismic events with local magnitude greater than 2.0 only.

Note that the RSNI "quasi-real-time" earthquake location procedure is, at the moment, used only for monitoring the local seismic activity in the southwestern Alps and northern Apennines (for which the mean source-receiver distance is generally less than $100 \mathrm{~km}$ ), and therefore, the problem related to regional or teleseismic phase association has not been still dealt with.

\section{Reference data}

The automatic procedures analyzed in this paper are developed and tuned in order to locate seismic events in the southwestern Alps and northern Apennines where the RSNI network operates since 1982 (Fig. 1). This area encompasses the western Alpine arc, the Ligurian Sea, and the northern Apennines and it has a great structural complexity and a wide lateral heterogeneity, coming from the continental collision due to the closure of the Alpine ocean in the Middle Tertiary (around $50 \mathrm{Ma}$ ) with a N-S to NNE-SSW directed motion between the European and the African plates and from the following anticlockwise rotation of the Adriatic microplate.

The selection of the seismic database used for testing the automatic location procedures is aimed to obtain a representative sample of the whole seismicity of such a heterogeneous area, mainly characterized by low-energy earthquakes ( $\mathrm{Ml}<$ 3.5) concentrated along the Alpine and the Apenninic chains (Fig. 1). The selection criteria are applied to manually revised location parameters and are based mainly on spatial distribution. The earthquakes taken from the RSNI database for 
Fig. 1 Seismic network configuration (RSNI, INGV, and ETH stations) and recorded seismicity (gray shaded circles) used as reference dataset in this study. Top right panel: local magnitude of the 575 selected events

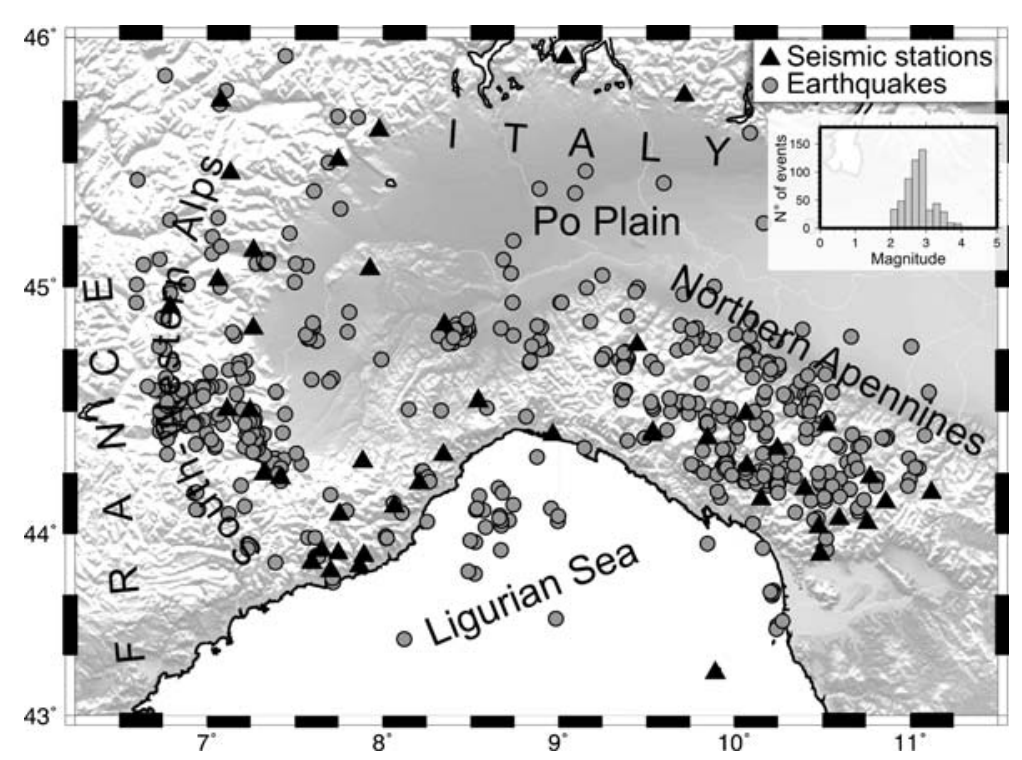

the period 2000-2007 have been geographically selected from $43^{\circ}$ to $46^{\circ}$ in latitude and from $6^{\circ} 30^{\prime} \mathrm{E}$ to $11^{\circ} 30^{\prime} \mathrm{E}$ in longitude, with local magnitude greater than 2.0. In order to exclude from the dataset a large number of events for which the location could not be potentially constrained (e.g., earthquakes located outside the network with a few readings), a selection in quality has been performed considering events with azimuthal gap lower than $240^{\circ}$ only. The resulting database consists of 575 earthquakes $(11,898 \mathrm{P}$ phases and 9,693 $\mathrm{S}$ phases manually revised) recorded from 30 seismic stations of the RSNI network. Starting from 2005, stations belonging to both ETH and INGV operating in the study area have been also considered in the manual and automatic location procedures. Manually revised P- and S-phase readings and hypocentral locations, computed by using Hypoellipse code (Lahr 1979) applied to the manual picks, are used as reference data to test automatic picking and automatic location algorithms, respectively.

An objective estimate of the location accuracy may be achieved by analyzing quarry blasts. Mainly in the southwestern sector of the considered area (Ligurian region) some quarries were energetic enough to be recorded by a significant number of stations (i.e., >8). In this paper, five blasts, with local magnitude spanning between 0.6 and 1.0, have been located with Hypoellipse and NonLinLoc codes applied to manually revised Pand S-phase picks. The obtained locations (black and gray circles in Fig. 2) have been compared with the center of each quarry (black crosses in Fig. 2); in summary, we can estimate an average error less than $500 \mathrm{~m}$ in the epicenter location and about $1.5 \mathrm{~km}$ in focal depth for locations derived from both Hypoellipse and NonLinLoc scheme. This test points out that the location derived from manually revised readings may be considered accurate and that the differences in the hypocenter parameters computed by applying Hypoellipse and NonLinLoc schemes are negligible. Since Hypoellipse code is routinely adopted to locate earthquakes by the RSNI network, it is here used to compute the reference locations.

Note that while the location procedure of Hypoellipse code, as adopted by RSNI, uses different 1D velocity models, calibrated for each station to take into account lateral heterogeneities, the location algorithm of NonLinLoc uses a full 3D velocity model of the whole volume of study. The 1D models adopted by Hypoellipse code are described and checked in Spallarossa et al. (2001) and they are derived from deep seismic profiles and tectonic constraints. The 3D model, adopted 
Fig. 2 Quarry blasts analysis: crosses indicate the position of quarries, circles indicate the location derived from manually revised data, and stars and triangles indicate the locations derived from $\mathrm{CF}$ and AIC automatic pickers, respectively. The black symbols indicate Hypoellipse locations whereas gray symbols indicate NonLinLoc location (see text for details)

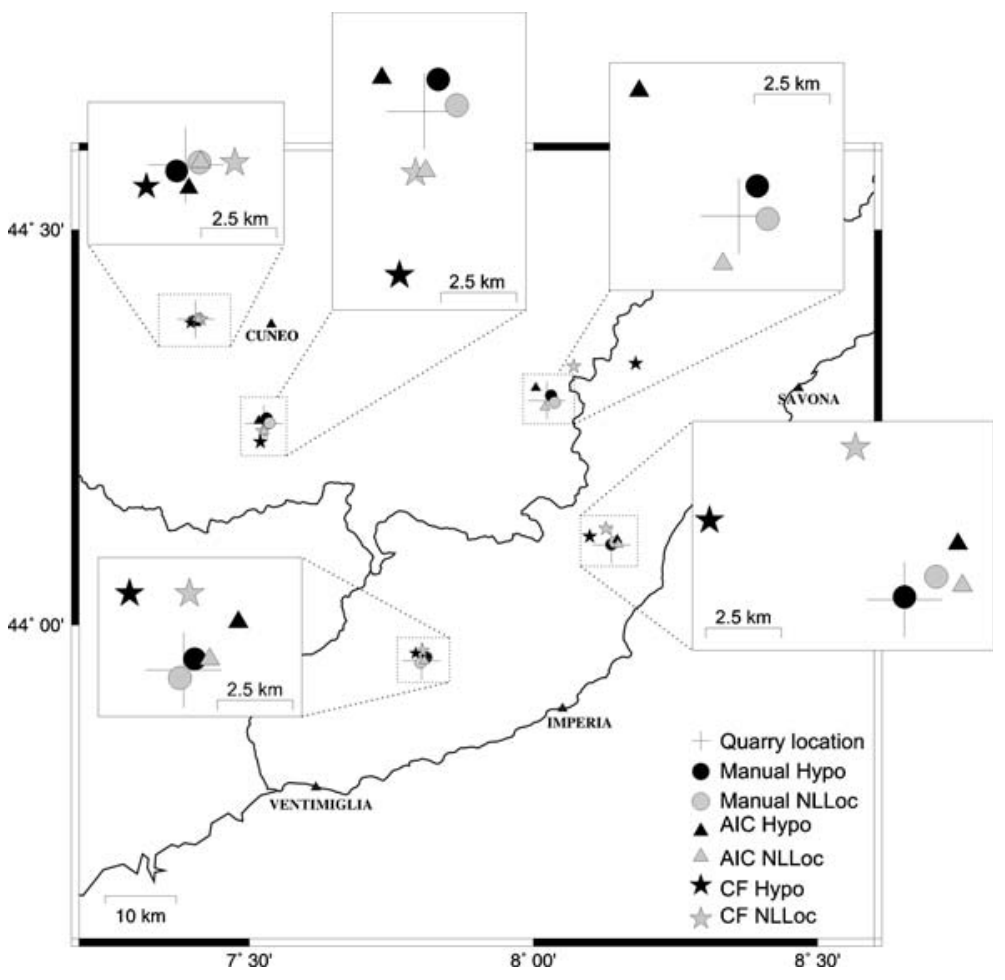

by NonLinLoc scheme, comes from a local tomography study by Scafidi et al. (2006) and it derives from a $3 \mathrm{D}$ inversion procedure computed by the software SIMULPS (Evans et al. 1994).

\section{Methodology}

Two different and independent approaches for automatic phase picking have been applied and tested in this study: the CF picker and the AIC picker. Here is a step-by-step description of each one (Fig. 3). Note that the CF picker provides arrival picks for which a measure of reliability (quality weight) is determined on the basis of the background noise level at event onset, the first difference at observed onset, and the peak amplitudes of the first three peaks (for detail, see Allen 1978); on the contrary, for the time being, the AIC picker does not assign quality weight to automatic readings (fixed quality weight). In Fig. 4, the behavior with time of the picking schemes is illustrated by means some examples.

\subsection{CF picker}

The first automatic picking procedure uses the traditional Allen's $(1978,1982)$ picking scheme based on the STA/LTA ratio applied on the following envelope function (Characteristic Function), sensitive to both amplitude and frequency:

$E(t)=f(t)^{2}+C_{2}+f^{\prime}(t)^{2}$.

In this equation, $f(t)$ is the seismogram, $f^{\prime}(t)$ is the first difference, and $C_{2}$ is a constant taking into account of the weight associated to $f(t)$ and $f^{\prime}(t)$, as a function of the digital sample rate and of the noise characterizing the seismic station.

The algorithm of Allen (1978) was created to detect P-phase arrival times on single traces recorded by one-component stations. However, since three-component stations are available in our dataset, a Characteristic Function for S-phase picking is also computed using the horizontal components. 

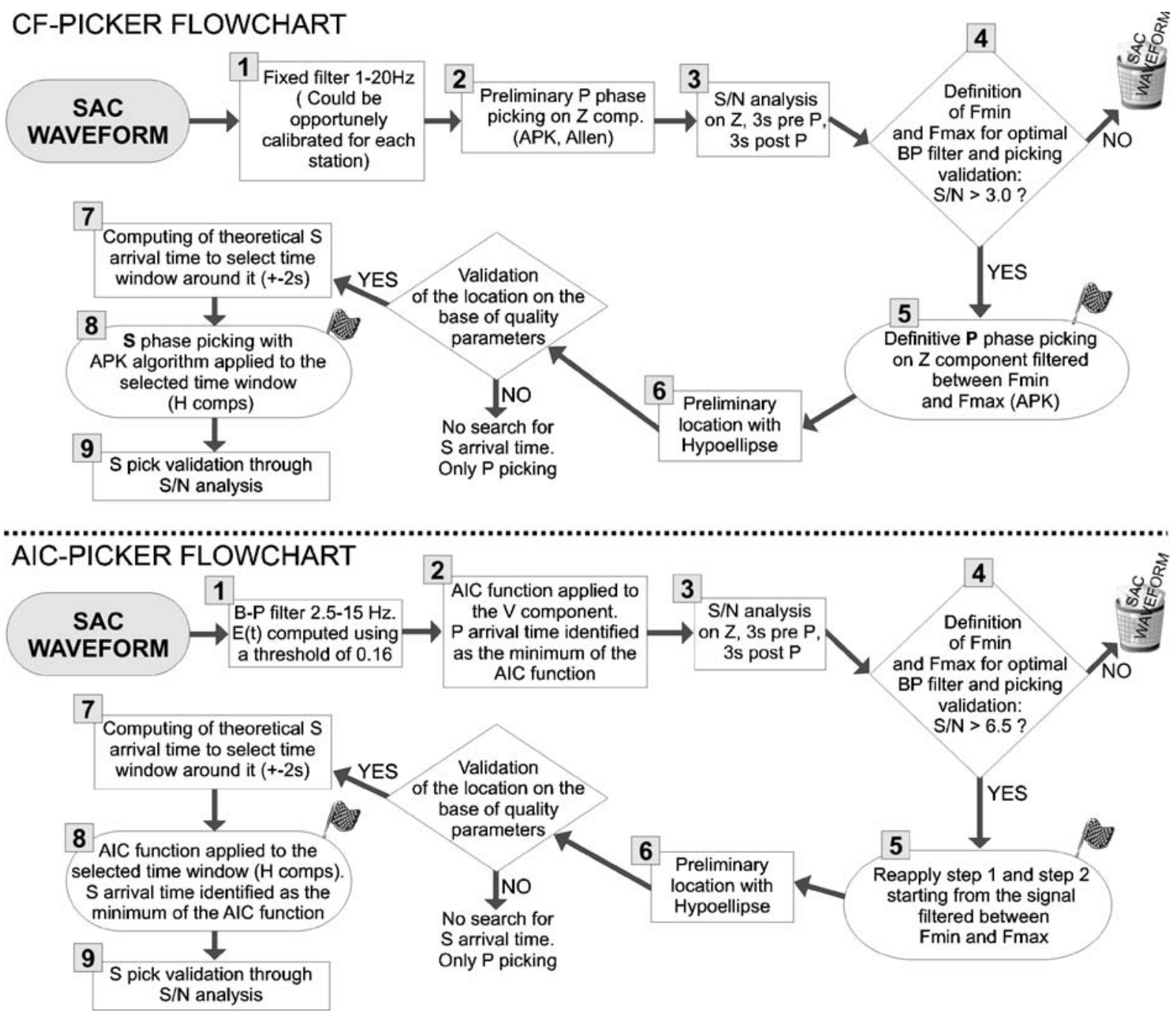

Fig. 3 Top panel: flow chart of the multistep processing scheme relative to the $\mathrm{CF}$ picker. Bottom panel: flow chart of the multistep processing scheme relative to the AIC picker. The number reported in the gray frames corresponds to the step number used in the text
Allen's algorithm is the base of the standard SAC autopicking command APK (Goldstein et al. 1999) that we use in our procedure. For a more indepth analysis of the automatic procedure, a stepby-step description follows (Figs. 3 and 4):

Step 1: Data are subjected to a preprocessing phase that consists in the application of a "fixed" band-pass filter carefully calibrated for each station on the basis of a trial-and-error procedure.
Step 2: A preliminary P-phase picking on the vertical component is performed using the APK function (SAC2000) based on Allen (1978). Although in the Sac2000 Command Reference Manual (http:// www.iris.edu/manuals/sac/manual.html) it is stated that most of the parameters of the function do not need to be changed, we performed some tests in order to optimize the algorithm performance for our dataset. The only parameter c5, used 

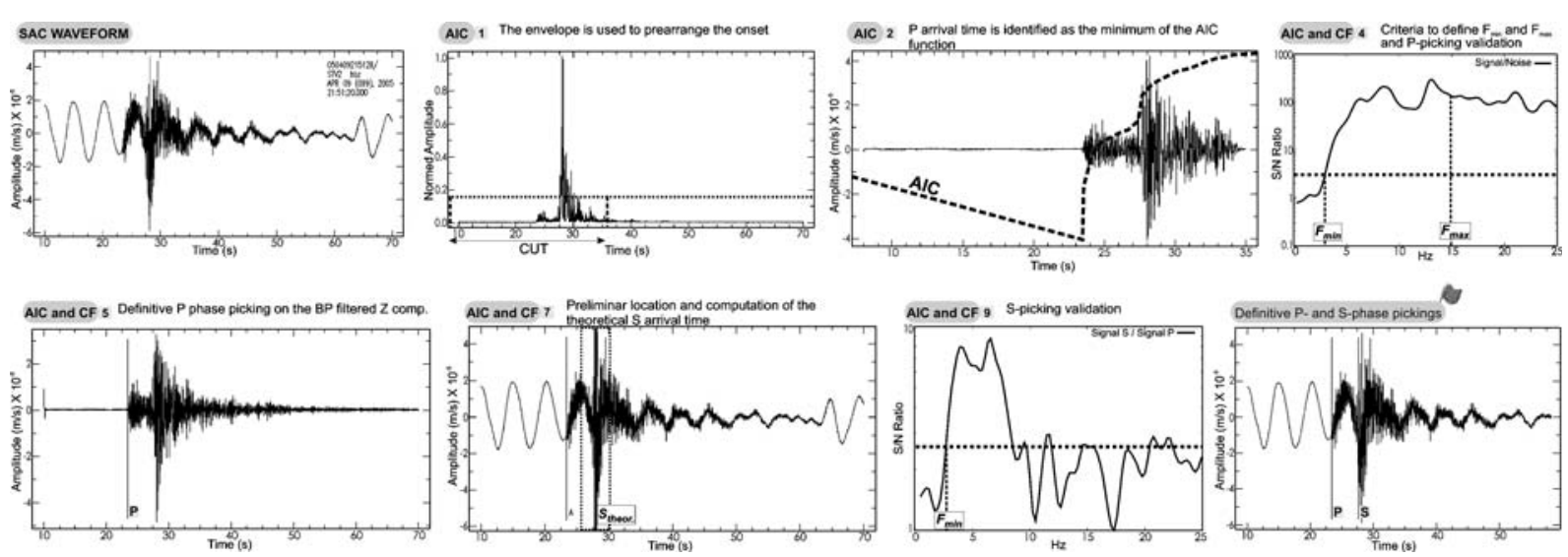

Fig. 4 Main steps of the picking schemes (CF and AIC picker) illustrated by examples. The number reported for each panel corresponds to the step number used in the text

to compute the threshold reference level to declare a potential event, has been modified to 4.5 instead of the default 5.0. The other parameters are set to the default values proposed by the Sac2000 Command Reference Manual (e.g., $C_{3}=$ 0.6 , the weight used to compute the STA of the Characteristic Function; $C_{4}=0.03$, the weight used to compute the LTA of the Characteristic Function; $D_{9}=1$, the duration in seconds used to initialize the LTA of Characteristic Function; the STA is set to averaging time as short as three samples). Unpicked data are removed from the automatic analysis.

Step 3: Signal-to-noise analysis $(\mathrm{S} / \mathrm{N})$ on the vertical component: Using the P pick as reference time, a 3-s pre-P window (noise) and a 3-s post-P window (signal) are defined. Then the signal-to-noise ratio is computed and analyzed to find the optimal band-pass filter frequencies $\left(F_{\min }\right.$ and $F_{\max }$ ).

Step 4: Criteria to define $F_{\min }$ and $F_{\max }$ and picking validation: Analyzing the $\mathrm{S} / \mathrm{N}$ ratio, $F_{\text {min }}$ is defined as the smallest frequency between 1 and $8 \mathrm{~Hz}$ for which the $\mathrm{S} / \mathrm{N}$ is higher than a threshold value (fixed at 3.0 after several tests; hereafter SN threshold); in the same way, $F_{\max }$ is defined as the greatest frequency between 9 and
$15 \mathrm{~Hz}$ for which the $\mathrm{S} / \mathrm{N}$ is higher than $\mathrm{SN}$ threshold. The original signal is then filtered between $F_{\min }$ and $F_{\max }$.

If $F_{\min }$ or $F_{\max }$ cannot be estimated (i.e., the $\mathrm{S} / \mathrm{N}$ ratio keeps lower than 3 between 1 and 8 or 9 and $15 \mathrm{~Hz}$ ), the waveform (and therefore the $\mathrm{P}$ pick) is removed from the automatic analysis of the event. The "variable" filter, based on the $\mathrm{S} / \mathrm{N}$ ratio, allows to define, for each event and station, a variable frequency band where $P$ phase is particularly evident and consequently detectable from the STA/LTA analysis computed by the APK algorithm.

Step 5: Definitive P-phase picking on the BPfiltered vertical component (by the APK function) is defined.

Step 6: A preliminary location based on the $\mathrm{P}$ readings is computed using the Hypoellipse code (Lahr 1979).

Step 7: If, considering location computed in step 6 , the number of phases is greater than 5 , the azimuthal gap is lower than $280^{\circ}$ and the distance of the third station is lower than $120 \mathrm{~km}$, the computation of the theoretical $\mathrm{S}$ arrival time is performed using a simplified velocity model, and a window of $4 \mathrm{~s}$ around it is selected.

Step 8: The S picking is defined within the selected window using the APK algorithm, considering the unfiltered signal. For the 
$3 \mathrm{C}$ recordings, the $\mathrm{S}$ picking is performed on each of the two horizontal components separately and the S-pick value observed on the recording with higher $\mathrm{S} / \mathrm{N}$ ratio (computed between 1 and $8 \mathrm{~Hz}$ ) is chosen as final pick.

Step 9: The final S pick is validated on the basis of $\mathrm{S} / \mathrm{N}$ ratio as for $\mathrm{P}$ pick; in particular, for S-phase pick validation, the $\mathrm{S} / \mathrm{N}$ ratio is computed considering 3-s window length pre- and post-S reading, the SN threshold is fixed to 2.5 , and if $F_{\text {min }}^{\mathrm{s}}$ cannot be estimated (i.e., the $\mathrm{S} / \mathrm{N}$ ratio keeps lower than 2.5 between 1 and $8 \mathrm{~Hz}$ ), the $\mathrm{S}$ pick is rejected.

\subsection{AIC picker}

Following the work of Morita and Hamaguchi (1984), based on that of Kitagawa and Akaike (1978), and the more recent approaches proposed by Sleeman and van Eck (1999) and mainly by Kurz et al. (2005), an adapted automatic picker based on the AIC is developed and tested. As stated by Zhang et al. (2003), an autoregressive AIC picker is accurate if the AIC is only applied to a part of the signal which contains the onset. The Hilbert transform is therefore used to prearrange the onset:

$H(t)=\frac{1}{\pi} \int_{-\infty}^{+\infty} \frac{R(u)}{t-u} d u$

where $H(t)$ is the Hilbert transform of the realtime dependent function $R(t), t$ denotes the time, and the singularity at $u=t$ is handled by taking the Cauchy principle value of the integral. The envelope time function $E(t)$ is calculated as:

$E(t)=\sqrt{R(t)^{2}+H(t)^{2}}$.

The onset of seismic signal is determined by calculating the AIC function directly from the time series $R(t)$ cut on the ground of the envelope time function (Maeda 1985).

$$
\begin{aligned}
\operatorname{AIC}\left(t_{\mathrm{k}}\right)= & t_{\mathrm{k}} \log \left(\operatorname{var}\left(R_{\mathrm{k}}\left(t_{\mathrm{k}}, 1\right)\right)\right)+\left(T_{\mathrm{k}}-t_{\mathrm{k}}-1\right) \\
& \times \log \left(\operatorname{var}\left(R_{\mathrm{k}}\left(1+t_{\mathrm{k}}, T_{\mathrm{k}}\right)\right)\right)
\end{aligned}
$$

where $R_{\mathrm{k}}$ indicates that only the chosen window containing the onset is taken. $T_{\mathrm{k}}$ is the last sample of the cut time series, $t_{\mathrm{k}}$ ranges through all samples of $R_{\mathrm{k}}$, and var denotes the variance function defined as:

$\operatorname{var}=\frac{1}{N-1} \sum_{i=1}^{N}\left(R_{i}-\bar{R}\right)^{2}$

( $N$ is the length of the signal)

$R_{\mathrm{k}}(a, b)$ means that the variance function is calculated taken all samples ranging from $a$ to $b$.

The P- and S-phase arrival times are detected selecting the minimum of the AIC function following a multistep procedure as following described (Figs. 3 and 4):

Step 1: The signal related to the vertical component is filtered by a band-pass filter between 2.5 and $15 \mathrm{~Hz}$ and then the envelope time function $(E(t))$ is computed. The envelope is used to prearrange the onset: Each envelope is squared and normed, so that a constant threshold can be applied to all signals. A threshold value of 0.16 has been empirically calibrated for our data. A window of $20 \mathrm{~s}$ before and $8 \mathrm{~s}$ after this point is then the cutoff of the signal.

Step 2: The AIC function is applied to the previously selected part of the signal (previously filtered between 2.5 and $15 \mathrm{~Hz}$ ) and the $\mathrm{P}$ arrival time is identified as the minimum of AIC function.

Step 3: Signal-to-noise analysis: same as step 3 of the CF picker

Step 4: Criteria to define $F_{\min }$ and $F_{\max }$ and picking validation: same as step 4 of the $\mathrm{CF}$ picker, except for the SN threshold values that is fixed to 6.5 after several tests

Step 5: If the pick is not rejected, the steps 1 and 2 are applied again starting from the signal filtered by a band-pass filter between $F_{\min }$ and $F_{\max }$ and recomputing the envelope time function and the AIC function.

Step 6: Preliminary location: same as for the step 6 of the CF picker 
Step 7: Validation of the preliminary location: same as for the step 7 of the CF picker

Step 8: The AIC function is applied to the selected window containing the theoretical $\mathrm{S}$ onset and the $\mathrm{S}$ arrival time is recognized as the minimum of AIC function (note that in the case of one-component station, the AIC is applied to vertical component; for three-component station, the S picking is performed on each of the two horizontal components separately and the S-pick value observed on the recording with higher $\mathrm{S} / \mathrm{N}$ ratio is chosen as final pick).

Step 9: S pick validation: same as for the step 9 of the CF picker

\subsection{Hypoellipse-based and NonLinLoc-based seismic location algorithms}

Two location procedures applied to automatic picked data are tested in this work: Hypoellipse (Lahr 1979) and NonLinLoc (Lomax et al. 2000). Since Hypoellipse is a traditional earthquake location program routinely used by seismologists, here we give only a short review and refer the reader to Lahr (1979) for a more detailed description of this method. Briefly, the software Hypoellipse is a computer program for determining the hypocenters of local or near regional earthquakes. Theoretical travel times are determined from horizontally layered velocity structures (considering a fixed $V_{\mathrm{p}} / V_{\mathrm{s}}$ ratio, tuned for the area under study to 1.68), and observed arrival times for the first arrival of $\mathrm{P}$ and $\mathrm{S}$ waves are used in the solutions. Each arrival may be weighted according to the reading clarity (assigned by the automatic picking procedure or by an operator), in order to take more into account mainly good data. Besides the reading weighting factor, the location algorithm considers weight factors also related to the epicentral distance to the station and the deviation of its residual from the mean. The hypocenter is found using Geiger's method (Geiger 1912) to minimize the RMS of the difference between observed and predicted arrival times. In this work, automatic seismic locations have been computed by using the following Hypoellipse weighting settings: the maximum distance (XNEAR) with as- signed weight multiplied by 1.0 (full weight) is $50 \mathrm{~km}$; the least distance (XFAR) with assigned weight multiplied by 0.0 (zero weight) is $400 \mathrm{~km}$.

The NonLinLoc software (Lomax et al. 2000) uses efficient global sampling algorithm to obtain an estimate of the posterior probability density function (PDF) in 3D space for the hypocenter location. The location PDF provides a complete description of likely hypocenter locations and includes comprehensive uncertainty information. The location algorithm follows the probabilistic formulation of inversion presented by Tarantola and Vallette (1982), Moser et al. (1992), and Wittlinger et al. (1993). This method makes available two different likelihood functions to build the PDF. The first function is the standard approach of the least squares, L2 norm (LS-L2). The second function is based on the equal differential time (EDT) formulation of Font et al. (2004) which is a generalization of the master station method (Zhou 1994). These approaches are extensions of the "method of hyperbolas" cited by Milne (1986). The EDT-likelihood function is proved to be more robust than LS-L2 in the presence of outliers (with a residual greater than its nominal error) in the data (Lomax 2005). With both likelihood functions, the errors in the seismic wave arrival times and in the forward problem for the travel time calculation are assumed to be Gaussian expressed by covariance matrices. This assumption allows the direct analytic calculation of a maximum likelihood origin time for the LS-L2 likelihood function, whereas the EDT determination is inherently independent of any origin time estimate. In this way, the 4D problem of hypocenter location reduces to a 3D search over latitude, longitude, and depth. This 3D search could be performed in three different ways (Lomax et al. 2000):

- Via a grid-search algorithm using successively finer nested grids

- Via a Metropolis-Gibbs sampling algorithm performing a directed random walk within a spatial volume to obtain a set of samples that follow the PDF

- Via an Oct-Tree Importance sampling algorithm, which gives accurate, efficient, and complete mapping of earthquake location 
PDFs in 3D space (Lomax and Curtis 2001). This algorithm uses recursive subdivision and sampling of rectangular cell in $3 \mathrm{D}$ space to generate a cascade structure of sampled cells. The density of sampled cells follows the PDF values of the cell center, thus leading to a higher density of cells in areas of higher PDF (lower misfit).

The location uncertainties are often shown as confidence volumes or confidence contours of arbitrary shape if the complete PDF is available (when obtained by the grid search algorithms) or by density plot if the complete PDF in not available (when obtained by Metropolis-Gibbs and Oct-Tree sampling algorithm). The final hypocenter location is given by its maximum likelihood (or minimum misfit) value or by the expectation hypocenter location (Gaussian estimator; Lomax et al. 2000; Lippitsch et al. 2005).

In this work, we locate automatically picked earthquakes adopting, in the NonLinLoc code, the EDT-likelihood function and the Oct-Tree algorithm (Lomax and Curtis 2001), considering $3 \mathrm{D}$ velocity model for $\mathrm{P}$ waves with a fixed $V_{\mathrm{p}} / V_{\mathrm{s}}$ ratio of 1.68. These program settings ensure the most reliable results.

\section{Results}

A preliminary estimate of the accuracy of the investigated automatic location procedures may be

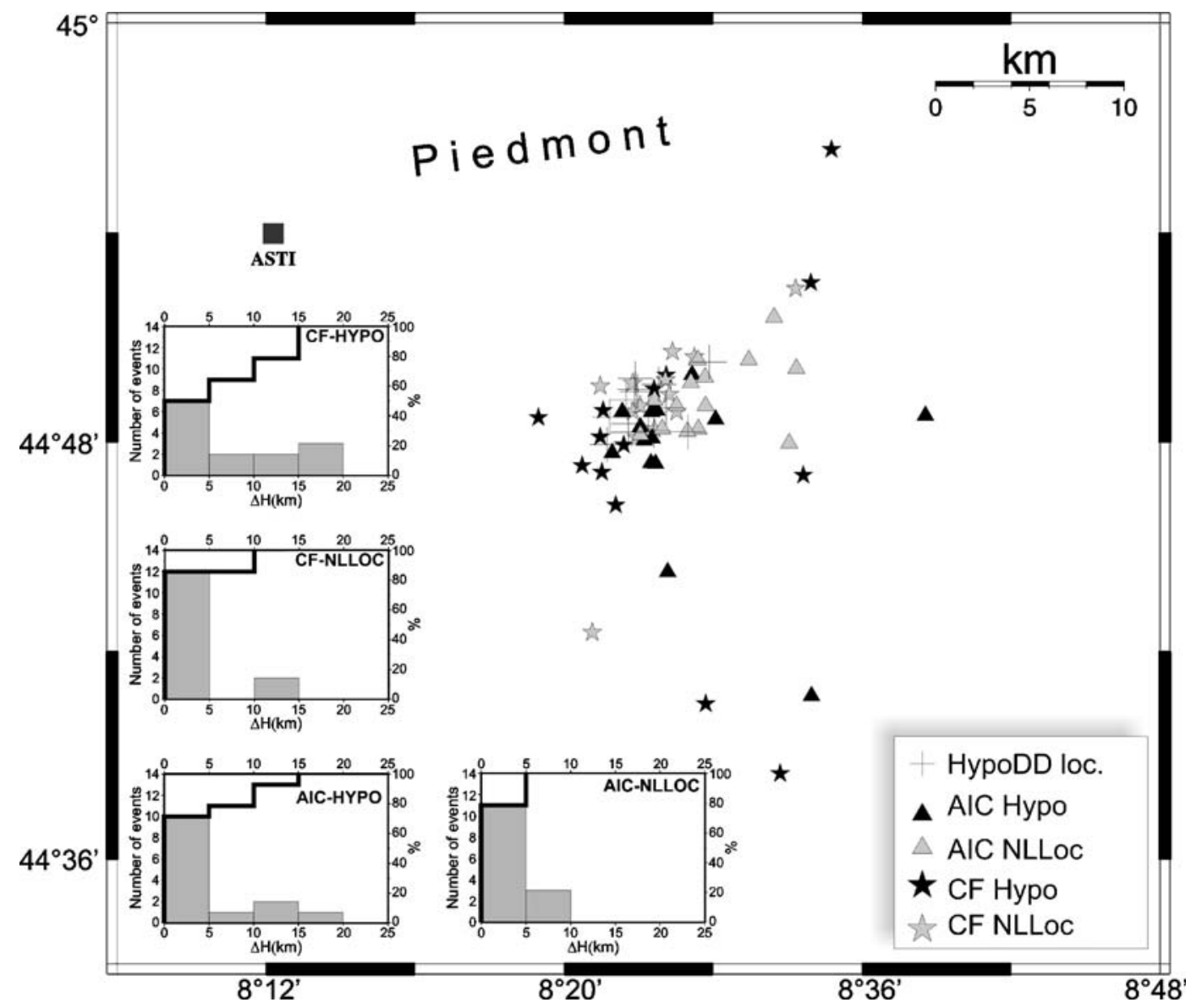

Fig. 5 Multiplet analysis: crosses indicate the position of the events as computed by Massa et al. (2006) and stars and triangles indicate the locations derived from $\mathrm{CF}$ and
AIC automatic pickers, respectively. The black symbols indicate Hypoellipse locations whereas gray symbols indicate NonLinLoc location (see text for details) 
derived from the analysis based on the five quarry blast analysis. As shown in Fig. 2, all automatic procedures lead to location (triangles and stars in Fig. 2) with an average epicentral difference less than $5 \mathrm{~km}$ with respect to the center of each quarry (black crosses in Fig. 2). Only in one case, the CF picker applied to both location schemes shown an epicentral error greater than $5 \mathrm{~km}$ (but lower than $10 \mathrm{~km}$ ). Regarding the depth, for all automatic procedures, we can estimate an average error less than $5 \mathrm{~km}$.

Another preliminary test is performed considering the multiplet analysis proposed by Massa et al. (2006). For these events, occurred in Piedmont region, very accurate relative locations, derived from a waveform similarity analysis, are available and can be used as reference data for testing the automatic location procedures. Among the events considered by Massa et al. (2006), 14 earthquakes have been picked out following the same criteria used for selecting the reference data. As shown in Fig. 5, all automatic procedures lead to location (triangles and stars in Fig. 5) with an average epicentral difference less than $10 \mathrm{~km}$ with respect to the locations computed by Massa et al. (2006) (black crosses in Fig. 5). The best results have been obtained for the AIC picker applied to both location schemes showing epicentral errors lower than $5 \mathrm{~km}$ for about $80 \%$ of events. In this text, we have just analyzed the difference encountered in terms of absolute coordinates; obviously, the reference locations only, obtained applying relative location method, lead to a sharp image of seismicity that may be correlate to the seismogenetic structure studied in Massa et al. (2006).

A more complete discussion is also proposed by considering the earthquake dataset. The comparison between automatic location schemes is

\section{CF - picker}
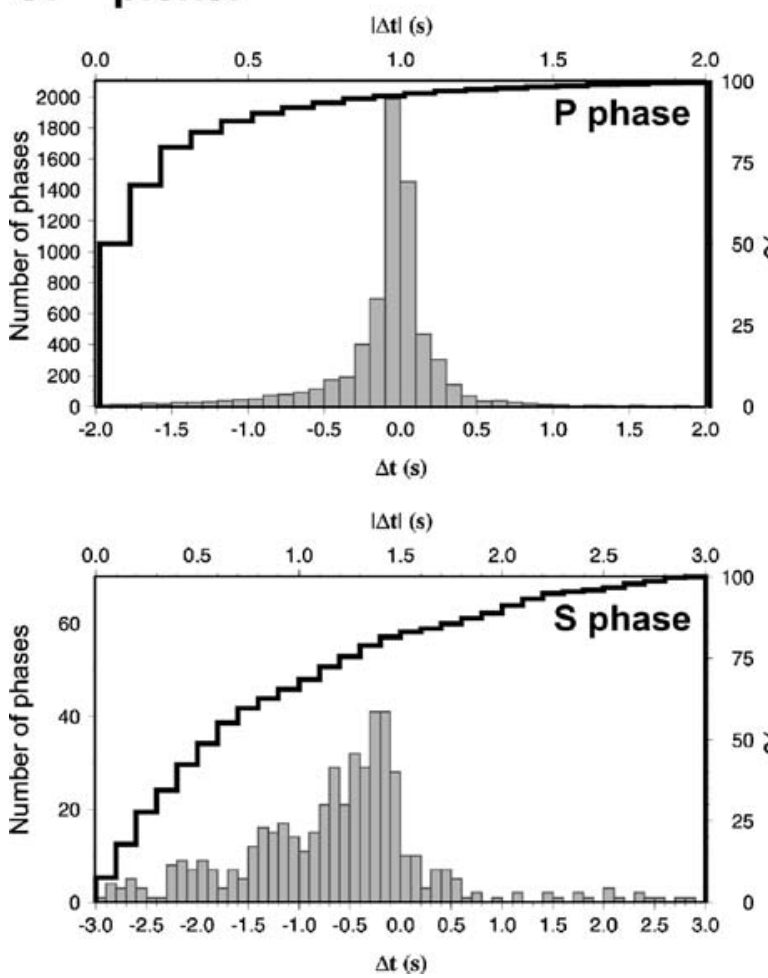

Fig. 6 Differences $(\Delta t)$ between the reference arrival times (manually picked) and the automatic ones (CF picker, left panels and AIC picker, right panels); each panel shows histograms and cumulative curves for $\mathrm{P}$ and $\mathrm{S}$ phase

\section{AIC - picker}
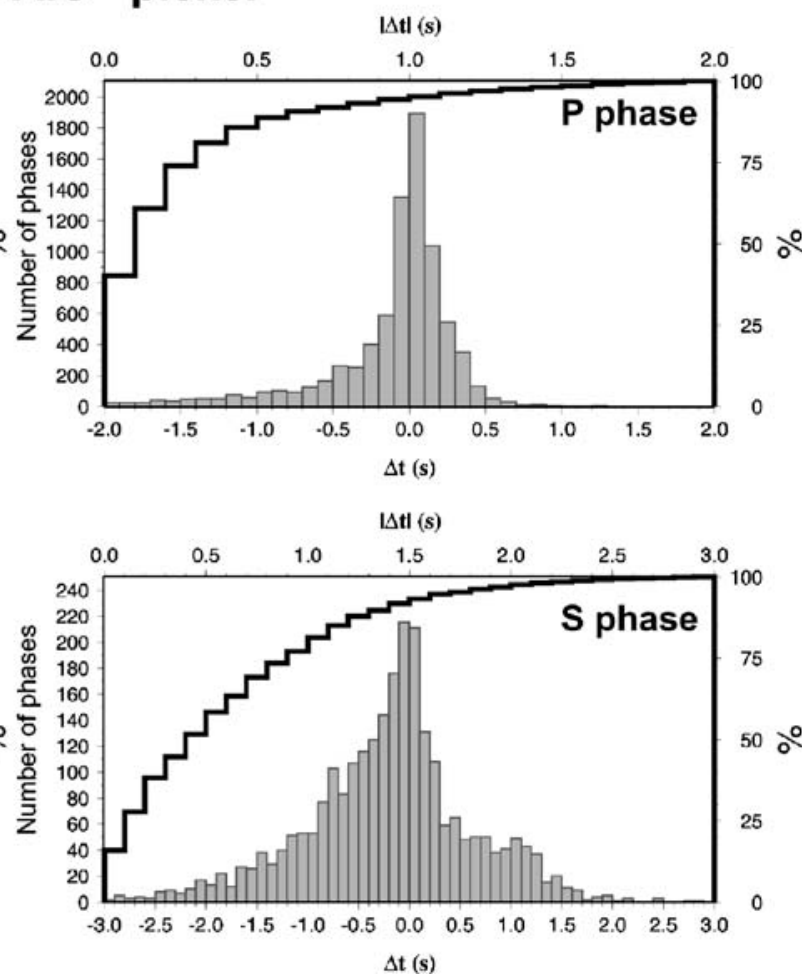

separately. The cumulative curves are computed from the absolute value of $\Delta t$ (see the scale on the upper side of histograms; note that the frequency percent are relative to the range of $\Delta t$ values considered in the plots) 
performed by a two-step procedure. In the first step, the differences between the manual reference P- and S-phase arrival times and the automatic readings, obtained by applying the $\mathrm{CF}$ and the AIC pickers, are evaluated and analyzed. The attention is focused on both number (quantity estimate) and magnitude of travel time differences with respect to manual readings (quality estimate) of automatic picks, recalling that a reliable automatic picking procedure should lead to the best compromise between number of recognized picks and quality of readings (i.e., small differences with respect to reference arrival times and small number of false picks) for both $\mathrm{P}$ and $\mathrm{S}$ phases. In the second step, differences in epicenter coordinates and depths are evaluated considering, as reference, the locations obtained by applying the manual readings to RSNI routine location procedure (Hypoellipse code). In detail, the CF picker readings and the AIC picker ones are applied as input travel times to both Hypoellipse and NonLinLoc location scheme. The four resulting datasets of automatic determined location parameters (hereinafter CF-HYPO, CF-NLLOC, AIC-HYPO, and AIC-NLLOC dataset) are compared with the reference one.

\subsection{Step 1 (CF picker versus AIC picker)}

Two sets of readings have been obtained by applying the two investigated automatic picking schemes to the 575 earthquakes. The CF picker has provided 7,127 P-phase arrival times and 691 S-phase arrival times with a mean number of readings per event equal to $14 \pm 5$. The AIC picker has provided 8,284 P-phase arrival times and 2,690 $\mathrm{S}$-phase picks with a mean number of readings per event equal to $17 \pm 7$.

In Fig. 6, differences between reference and automatic readings (reference time minus automatic one) are reported for both pickers considering $\mathrm{P}$ and $\mathrm{S}$ phases separately. Regarding $\mathrm{P}$ phases, the AIC picker has provided $83 \%$ of readings with differences lower than $0.5 \mathrm{~s}$ and $9.5 \%$ of reading with differences greater than $1 \mathrm{~s}$ and a median value of $0.00 \mathrm{~s}$. Instead, the CF picker has provided $82 \%$ of readings with differences lower than $0.5 \mathrm{~s}$ and $10 \%$ of reading with differences greater than $1 \mathrm{~s}$ and a median value of $-0.03 \mathrm{~s}$.

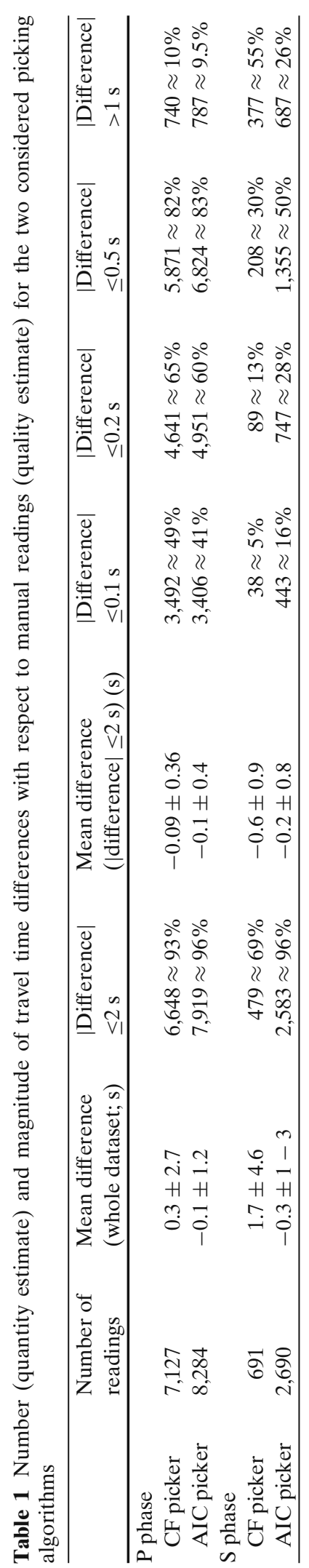



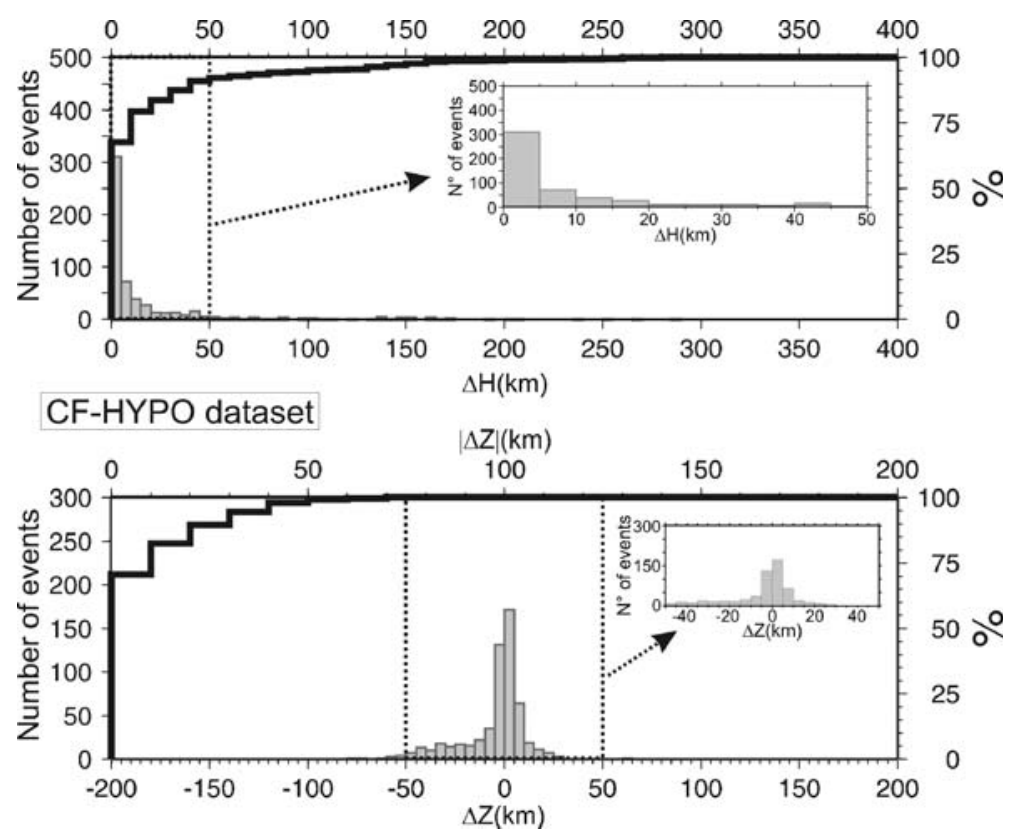

Fig. 7 Histograms of the differences between the manual reference location and those derived from analysis of $\mathrm{CF}$ HYPO dataset (Hypoellipse scheme applied to automatic readings derived from $\mathrm{CF}$ picker). Each panel shows histograms and cumulative curves for epicentral $(\Delta H)$ and depth $(\Delta Z)$ differences. For depth differences, the cumulative curve is computed from the absolute value of $\Delta Z$ (see the scale on the upper side of the depth difference histograms). The top right panels are enlargements of the histograms
About S phases, the AIC picker has provided 50\% of readings with differences lower than $0.5 \mathrm{~s}$ and $26 \%$ of reading with differences greater than $1 \mathrm{~s}$ and a median value of $-0.15 \mathrm{~s}$; the CF picker has provided $30 \%$ of readings with differences lower than $0.5 \mathrm{~s}$ and $55 \%$ of reading with differences greater than $1 \mathrm{~s}$ and a median value of $-0.25 \mathrm{~s}$. In Table 1, statistical results concerning the quantity
Fig. 8 Same as Fig. 4 but for the CF-NNLOC dataset (NonLinLoc scheme applied to automatic readings derived from $\mathrm{CF}$ picker)
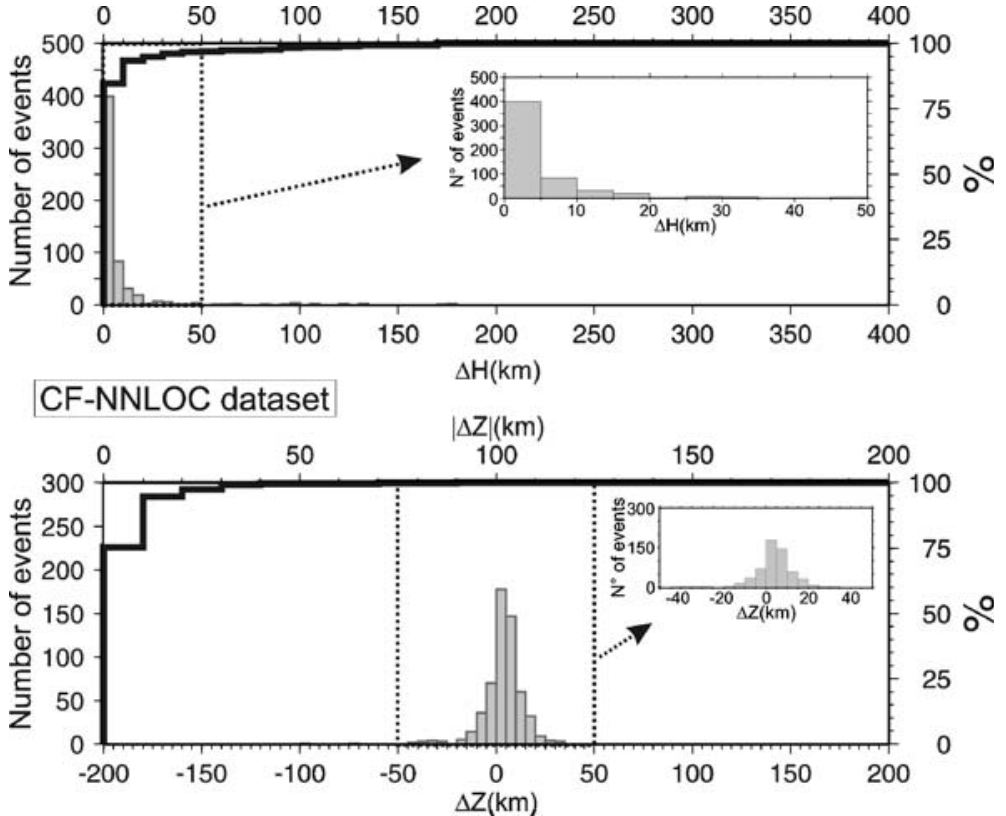
Fig. 9 Same as Fig. 4 but for the AIC-HYPO dataset (Hypoellipse scheme applied to automatic readings derived from AIC picker)
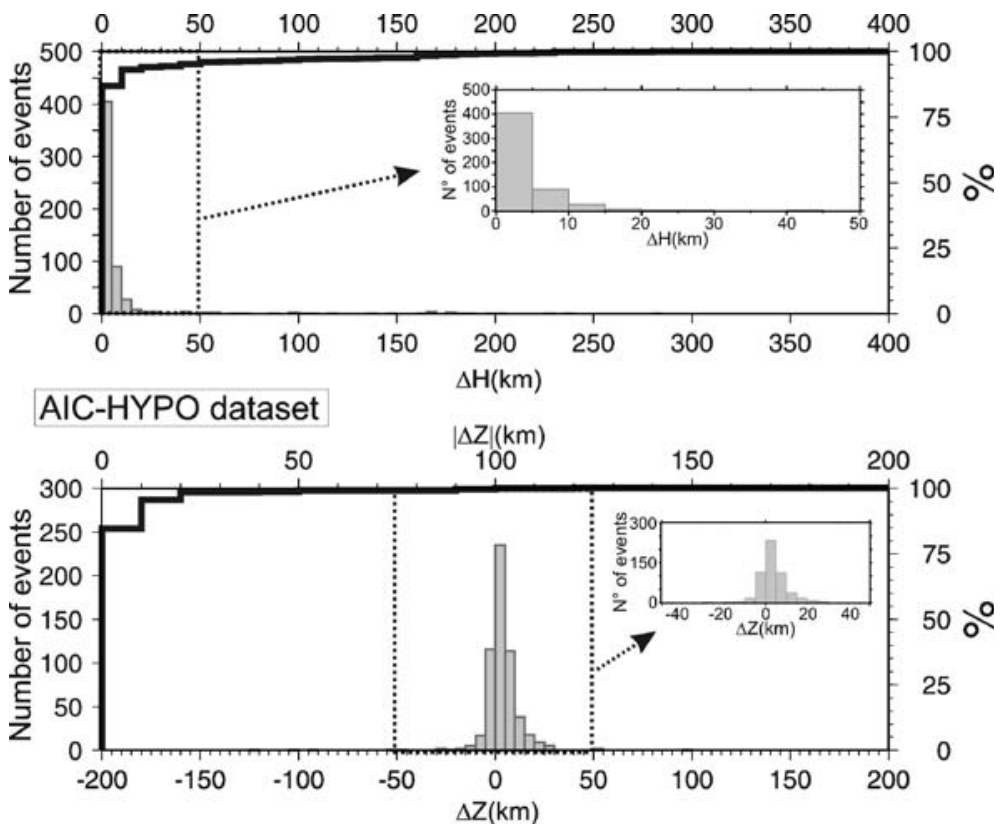

and quality estimates for the two automatic picking procedures are summarized.

\subsection{Step 2 (CF-HYPO, CF-NLLOC, AIC-HYPO, and AIC-NLLOC datasets)}

The automatic location reliability was evaluated by analyzing the differences between the reference location of the selected 575 earthquakes, computed by using Hypoellipse code (Lahr 1979) and the locations obtained applying the automatic algorithms. The histograms of these differences are shown in Figs. 7, 8, 9, and 10. Table 2 summarizes the main results of the location analysis.

The results can be summarized as follows:

CF-HYPO results (automatic readings derived from $\mathrm{CF}$ picker used in Hypoellipse
Fig. 10 Same as Fig. 4 but for the AIC-NNLOC dataset (NonLinLoc scheme applied to automatic readings derived from AIC picker)
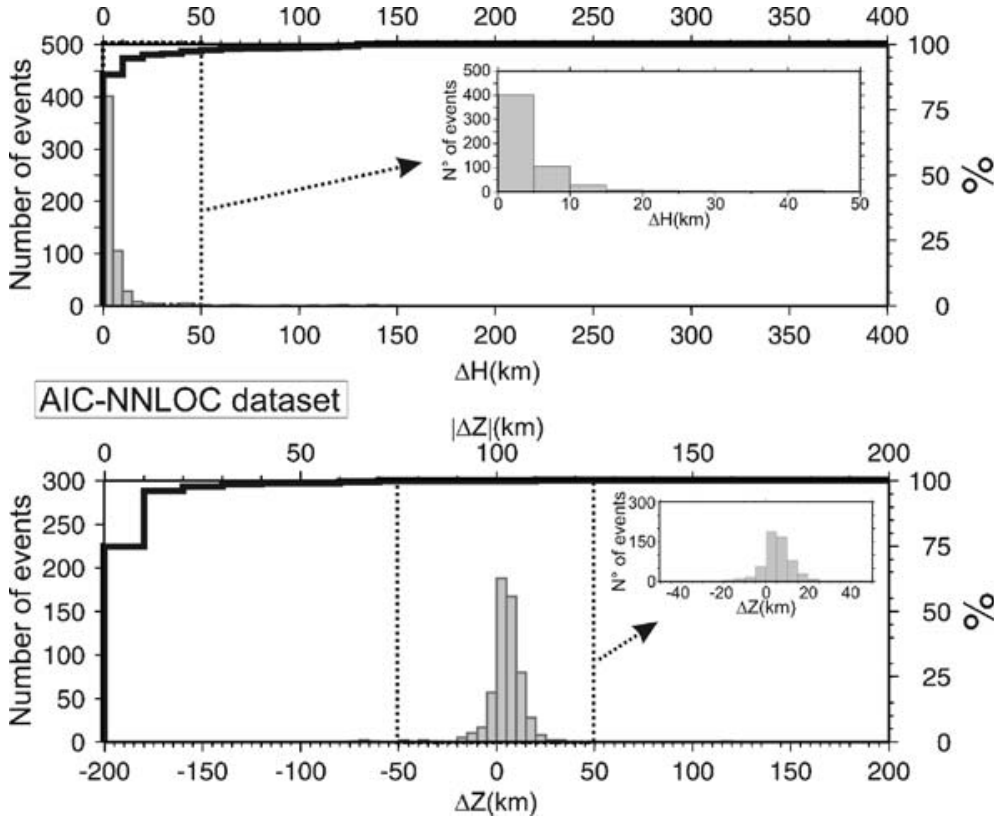


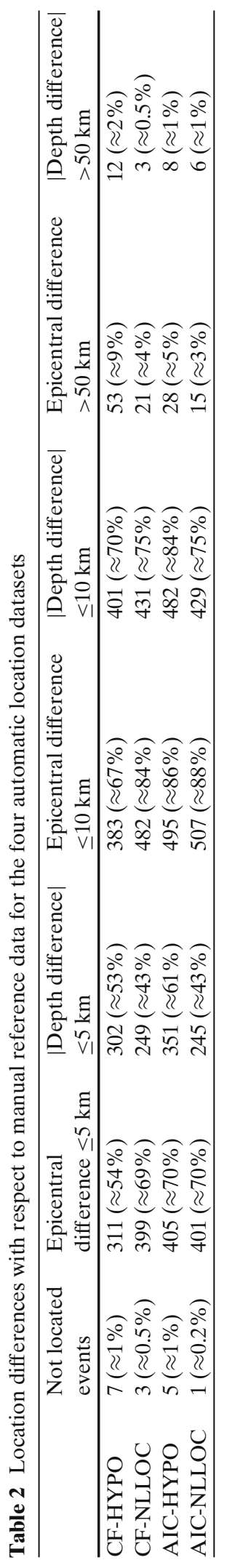

location scheme): The automatic algorithm allowed us to localize 568 events. The percentage of earthquakes localized with an epicentral difference less than $10 \mathrm{~km}$ is $67 \%$ and that with epicentral difference greater than $50 \mathrm{~km}$ is $9 \%$.

CF-NLLOC results (automatic readings derived from $\mathrm{CF}$ picker used in NonLinLoc location scheme): The automatic algorithm allowed us to localize 572 events. The percentage of earthquakes localized with an epicentral difference less than $10 \mathrm{~km}$ is $84 \%$ and that with epicentral difference greater than $50 \mathrm{~km}$ is $4 \%$.

AIC-HYPO results (automatic readings derived from AIC picker used in Hypoellipse location scheme): The automatic algorithm allowed us to localize 570 events. The percentage of earthquakes localized with an epicentral difference less than $10 \mathrm{~km}$ is $86 \%$ and that with epicentral difference greater than $50 \mathrm{~km}$ is $5 \%$. Moreover, the percentage of earthquakes localized with an epicentral difference less than $5 \mathrm{~km}$ is $70 \%$.

AIC-NLLOC results (automatic readings derived from AIC-picker used in NonLinLoc location scheme): The automatic algorithm allowed us to localize 574 events. The percentage of earthquakes localized with an epicentral difference less than $10 \mathrm{~km}$ is $88 \%$ and that with epicentral difference greater than $50 \mathrm{~km}$ is $3 \%$. Moreover, the percentage of earthquakes localized with an epicentral difference less than $5 \mathrm{~km}$ is $70 \%$.

Another test has been performed computing for each dataset the average weighted root mean square (wrms) defined as follow:

wrms $=\frac{\sum_{i=1}^{\text {n..events }} w_{i} \times \text { r.m.s. } i}{\sum_{i=1}^{\text {n.events }} w_{i}}$

where $w_{i}$ is the number of phases used for locating the $i$ th event and r.m.s. $i$ is the root mean square travel time residual of the $i$ th event. The wrms is equal to $0.24 \mathrm{~s}$ for the reference dataset and equal to $0.46,0.35,0.42$, and $0.33 \mathrm{~s}$ for the CF-HYPO, 

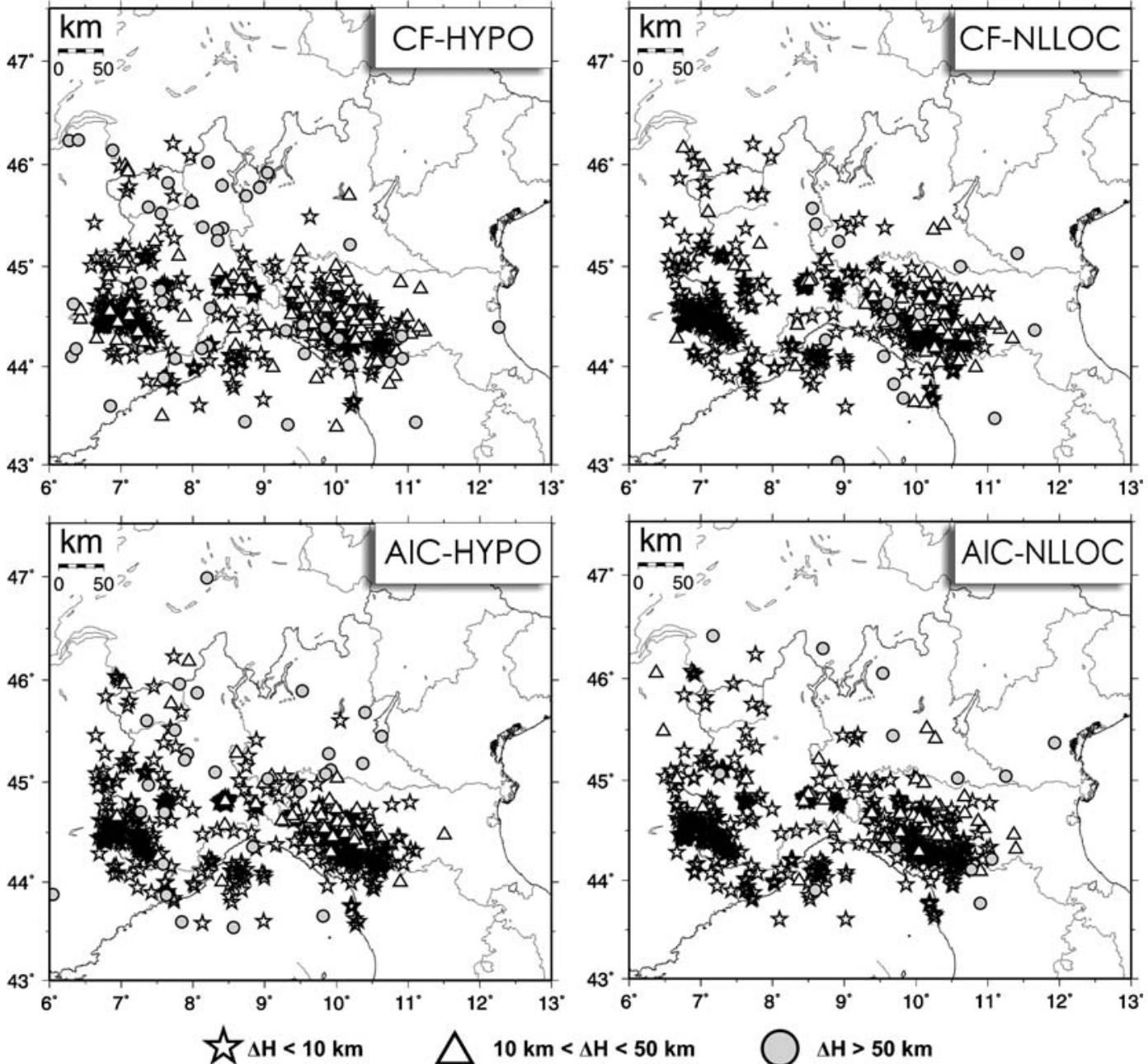

Fig. 11 Distribution of automatically located events as a function of epicentral differences between manual and automatic procedures for each analyzed datasets; different symbols indicate different epicentral difference range

Table 3 Relationship between azimuthal gap and location differences with respect to manual reference data for the four automatic location datasets

\begin{tabular}{llllc}
\hline & & $\begin{array}{l}\text { Epicentral difference } \\
\leq 10 \mathrm{~km}\end{array}$ & $\begin{array}{l}10 \mathrm{~km}<\text { epicentral } \\
\text { difference } \leq 50 \mathrm{~km}\end{array}$ & $\begin{array}{c}\text { Epicentral difference } \\
>50 \mathrm{~km}\end{array}$ \\
\hline CF-HYPO & $\mathrm{GAP} \leq 180^{\circ}$ & 202 & 34 & 8 \\
& $180^{\circ}<\mathrm{GAP} \leq 270^{\circ}$ & 165 & 71 & 14 \\
& $\mathrm{GAP}>270^{\circ}$ & 16 & 27 & 31 \\
CF-NLLOC & $\mathrm{GAP} \leq 180^{\circ}$ & 241 & 17 & 2 \\
& $180^{\circ}<\mathrm{GAP} \leq 270^{\circ}$ & 222 & 14 & 4 \\
AIC-HYPO & $\mathrm{GAP}>270^{\circ}$ & 19 & 11 & 15 \\
& $\mathrm{GAP} \leq 180^{\circ}$ & 288 & 30 & 3 \\
& $180^{\circ}<\mathrm{GAP} \leq 270^{\circ}$ & 204 & 6 & 12 \\
AIC-NLLOC & $\mathrm{GAP}>270^{\circ}$ & 9 & 13 \\
& $\mathrm{GAP} \leq 180^{\circ}$ & 277 & 28 & 1 \\
& $180^{\circ}<\mathrm{GAP} \leq 270^{\circ}$ & 223 & 15 & 3 \\
& $\mathrm{GAP}>270^{\circ}$ & 7 & & 11 \\
\hline
\end{tabular}


CF-NLLOC, AIC-HYPO, and AIC-NLLOC, respectively.

As shown in Fig. 11, the plot of the geographical position of the automatic locations as a function of epicentral difference with respect to the reference locations evidences the different level of reliability of the analysed procedures: As expected, for all datasets, the most accurate automatic earthquake locations are obtained in the areas with a better station coverage (Fig. 1).

The relationship between azimuthal gap, defined as the largest azimuthal separation in degrees between stations, for which at least one automatic reading is available, as seen from the epicenter, and the epicentral differences with respect to the reference locations is shown in Table 3. Except for CF-HYPO dataset, more than $80 \%$ of locations for which the azimuthal gap is less than $270^{\circ}$ shows epicentral differences lower than $10 \mathrm{~km}$.

\section{Conclusions}

In this paper, two automatic picking schemes and two location methods are analyzed and compared with the aim of selecting the most suitable automatic procedure for locating seismic events in southwestern Alps and northern Apennine by using RSNI network. The reliability of each automatic procedure is defined by comparing automatic readings and automatic location coordinates with reference values derived from manually revised data. It is worth noting that all tuning parameter (such as filtering ranges, $\mathrm{S} / \mathrm{N}$ thresholds, AIC threshold, location weights, and so on) adopted by the algorithms (both pickers and location schemes) are carefully calibrated by trial and error procedure applied to our reference dataset in order to obtain the best results (i.e., automatic readings as much similar as possible to manual ones and hypocentral coordinates as much similar as possible to manual ones).

The main conclusions of this study can be summarized as follows:

- Regarding $\mathrm{P}$ phases, the CF picker and the AIC picker provide very similar results in term of magnitude of travel time differences with respect to manual picks (travel times difference less than $0.5 \mathrm{~s}$ for more than $80 \%$ data) even though the AIC picker leads to a larger number of picks than CF picker $(8,284$ versus 7,127$)$. Note that the small number of picks with travel time differences greater than $\pm 0.5 \mathrm{~s}$ is related to the quality of the picking engines (STA/LTA detector or Akaike Information Criterion) and to the pick validation criteria included in the two procedures (steps 4 and 9)

- Regarding S phase, on the contrary, the two picking algorithms strongly differ: The AIC picker provides larger number of picks than CF picker (2,690 versus 691) with a lower magnitude of travel time differences with respect to manual picks; the number of automatic picks with differences greater than $1 \mathrm{~s}$ is reduced from $55 \%$ for $\mathrm{CF}$ picker data to $26 \%$ for AIC picker data. Although the use of $\mathrm{CF}$ picker may be considered as proper as AIC picker for automatic picking of $\mathrm{P}$ phases, AIC picker is proved to be more suitable than $\mathrm{CF}$ picker for (rightly) recognising $S$ phases; therefore, the AIC picker provides more information (readings) for, potentially, computing more constrained and reliable location than $\mathrm{CF}$ picker, mainly regarding the definition of the focal depth

- Using Hypoellipse scheme, the epicentral locations found starting from AIC picker readings are more reliable that those derived from CF picker showing a percentage of earthquakes located with epicentral difference less than $5 \mathrm{~km}$ of $70 \%$ instead of $54 \%$

- The NonLinLoc location scheme leads to similar results using both $\mathrm{CF}$ picker and AIC picker (epicentral difference less than $5 \mathrm{~km}$ for about $70 \%$ of data); therefore, the NonLinLoc code seems to be less sensitive than Hypoellipse in computing reliable locations even if the number and the quality of available readings is not optimal and mainly when reliable $\mathrm{S}$ phases are lacking

- Starting from the same automatic readings, the number of events localized with epicentral difference greater than $10 \mathrm{~km}$ is strongly reduced when using the NonLinLoc location scheme instead of Hypoellipse; when 
automatic picker provides few and/or unreliable data, the NonLinLoc code seems to be more robust than Hypoellipse, seldom leading to unreliable locations (i.e., epicentral difference greater than $10 \mathrm{~km}$ )

- For all automatic location procedures, the number of not located events and events with epicentral differences greater than $50 \mathrm{~km}$ is very low (about 1\% for all datasets). This is strictly related to the presence of a very limited number of wrong picks per event for which the location schemes (both Hypoellipse and NonLinLoc) succeeded in recognising outliers, almost always leading to reliable hypocentral coordinates

- Regarding depth differences, the use of Hypoellipse scheme coupled with AIC picker provides the most reliable results (depth difference less than $5 \mathrm{~km}$ for $61 \%$ of locations and greater than $10 \mathrm{~km}$ for $15 \%$ only); however, the NonLinLoc scheme is proved to be more robust than Hypoellipse leading to reliable results even if the number and the quality of S-phase picks is poor (e.g., depth difference less than $10 \mathrm{~km}$ for $75 \%$ of events for $\mathrm{CF}$ NLLOC dataset)

- Considering the wrms values, the best results are obtained for the AIC-NLLOC procedure whereas Hypoellipse scheme applied to automatic readings, derived from both $\mathrm{CF}$ and AIC picker, leads to values almost equal to twice the wrms of reference locations

It is worth noting that these conclusions are strictly related to the characteristics of the reference seismic events, representative of the seismicity of the southwestern Alps and northern Apennines and of the RSNI network geometry. In this context, the most reliable automatic location procedure suitable for locating seismic events by the RSNI network is proved to be obtained by using the AIC picker readings as input for the NonLinLoc location scheme.

Acknowledgements The GMT system software (Wessel and Smith 1991) is used for the figures. We thank two anonymous reviewers and the editor in chief T. Dahm for their helpful suggestions and comments that allow us to improve the manuscript significantly.

\section{References}

Allen RV (1978) Automatic earthquake recognition and timing from single traces. Bull Seismol Soc Am 68(5):1521-1532

Allen RV (1982) Automatic phase pickers: their present use and future prospects. Bull Seismol Soc Am 72(6):S225-S242

Akaike H (1974) Markovian representation of stochastic processes and its application to the analysis of autoregressive moving average process. Ann Inst Stat Math 26:363-387. doi:10.1007/BF02479833

Billings DS, Sambridge MS, Kennet BL (1994) Errors in hypocenter location: picking, model, and magnitude dependence. Bull Seismol Soc Am 84:1978-1990

Chiaruttini C (1991) Focus-of-attention techniques in the automatic interpretation of seismograms. Pure Appl Geophys 135:61-75. doi:10.1007/BF00877009

Dai H, MacBeth C (1995) Automatic picking of seismic arrivals in local earthquake data using an artificial neural networks. Geophys J Int 120:758-774

Earle PS, Shearer M (1994) Characterization of global seismograms using an automatic-picking algorithm. Bull Seismol Soc Am 84:366-376

Evans JR, Pitt AM (1995) Reliable automatic detection of long period volcanic earthquakes at Long-Valley Caldera, California. Bull Seismol Soc Am 85:15181522

Evans JR, Eberhart-Phillips D, Thurber CH (1994) User's manual for Simulps12 for imaging $\mathrm{Vp}$ and $\mathrm{Vp} / \mathrm{Vs}$ : a derivative of the "Thurber" tomographic inversion simul3 for local earthquakes and explosions. US Geol Surv Open-file Rept, pp 94-431

Ferretti G, Morasca P, Scafidi D, Spallarossa D, Turino C, Eva C (2008) Near real time and automatic capabilities of the renewed Regional Seismic Network of North Western Italy (RSNI). ESC 2008, Hersonissos, Crete, Greece, 7-12 September 2008

Fletcher JB, Baker LM, Spudich P, Goldestein P, Sims JD, Hellweg M (1992) The USGS Parkfield, California, dense seismograph array: UPSAR. Bull Seismol Soc Am 85:1518-1522

Font Y, Kao H, Lallemand S, Liu C-S, Chiao L-Y (2004) Hypocentral determination offshore eastern Taiwan using the maximum intersection method. Geophys J Int 158:655-675. doi:10.1111/j.1365-246X.2004.02317.x

Geiger L (1912) Probability method for the determination of earthquake epicentres from the arrival time only, (translated from Geiger's 1910 German article). Bull St Louis Univ 8(1):56-71

Goldstein P, Dodge D, Firpo M (1999) SAC2000: signal processing and analysis tools for seismologists and engineers, UCRL-JC-135963. Invited contribution to the IASPEI International Handbook of Earthquake and Engineering Seismology

Goldstein P, Dodge D, Firpo M, Minner L (2003) SAC2000: signal processing and analysis tools for seismologists and engineers. In: Lee WHK, Kanamori H, Jennings PC, Kisslinger C (eds) Invited contribution to The IASPEI international handbook of 
earthquake and engineering seismology. Academic, London

Gomberg JS, Shedlock KM, Roecker SW (1990) The effect of S-wave arrival times on the accuracy of hypocenter estimation. Bull Seismol Soc Am 80:1605-1628

Johnson CE, Lindh AG, Hirshorn B (1994) Robust regional phase association. USGS Open File Report, pp 94-621

Kitagawa G, Akaike H (1978) A procedure for the modelling of non-stationary time series. Ann Inst Stat Math 30(Part B):351-363

Kurz JH, Grosse CU, Reinhardt H (2005) Strategies for reliable automatic onset time picking of acoustic emissions and of ultrasound signals in concrete. Ultrasonics 43(7):538-564. doi:10.1016/j.ultras.2004.12.005

Lahr JC (1979) HYPOELLIPSE: a computer program for determining local earthquake hypocentral parameters, magnitude, and first-motion pattern. U S Geological Survey Open-File Report, pp 79-431

Lienert BR (1997) Assessment of earthquake location accuracy and confidence region estimate using known nuclear tests. Bull Seismol Soc Am 87:11501157

Lippitsch R, White RS, Soosalu H (2005) Precise hypocentre relocation of microearthquake in hightemperature geothermal field: the Torfajökull central volcano, Iceland. Geophys J Int 160:370-387. doi:10.1111/j.1365-246X.2005.02467.x

Lomax A (2005) A reanalysis of the hypocentral location and related observations for the great 1906 California earthquake. Bull Seismol Soc Am 91:861877. doi:10.1785/0120040141

Lomax A, Curtis A (2001) Fast, probabilistic earthquake location in 3D models using oct-tree importance sampling. Geophys Res Abstr 3:955

Lomax A, Virieux J, Volant P, Berge C (2000) Probabilistic earthquake location in $3 \mathrm{D}$ and layered models: introduction of a Metropolis-Gibbs method and comparison with linear locations. In: Thurber $\mathrm{CH}$, Rabinowitz $\mathrm{N}$ (eds) Advances in seismic event location. Kluwer, Amsterdam, pp 101-134

Maeda N (1985) A method for reading and checking phase times in auto-processing system of seismic wave data. Zisin= Jishin 38:365-379

Massa M, Eva E, Spallarossa D, Eva C (2006) Detection of earthquake clusters on the basis of waveform similarity: an application in the Monferrato region (Piedmont, Italy). J Seismol 10:1-22. doi:10. 1007/s10950-006-2840-4

Milne J (1886) Earthquakes and other earth movements. Appelton, New York, p 361

Morita Y, Hamaguchi H (1984) Automatic detection of onset time of seismic waves and its confidence interval using the autoregressive model fitting. Zisin 37:281293

Moser TJ, van Ech T, Nolet G (1992) Hypocenter determination in strongly heterogeneous earth models using the shortest path method. J Geophys Res 97:65366572. doi:10.1029/91JB03176

Patanè D, Ferrari F (1999) ASDP: a PC-based program using a multi-algorithm approach for automatic detection and location of local earthquakes. Phys Earth Planet Inter 113:57-74

Pavlis GL (1986) Appraising earthquake hypocentre location errors: a complete, practical approach for single event locations. Bull Seismol Soc Am 76:1699-1717

Pujol P (1996) An integrated 3D velocity inversionjoint hypocentral determination relocation analysis of events in the Northridge area. Bull Seismol Soc Am 86:S138-S155

Rong-Song J (1999) Epicenter estimation using erroneous crustal model(s) and skew regional networks. Phys Earth Planet Inter 113:303-319. doi:10.1016/ S0031-9201(99)00009-6

Ruud BO, Husebye ES (1993) A new three-component detector and automatic single-station bulletin production. Bull Seismol Soc Am 82:221-237

Ruud BO, Lindholm CD, Husebye ES (1993) An exercise in automatic seismic record analysis and network bulletin production. Bull Seismol Soc Am 83:660-679

Scafidi D, Solarino S, Eva C (2006) Structure and properties of the Ivrea body and of the Alps-Apennines system as revealed by local earthquake tomography. Boll Geofis Teor Appl 47(3):497-514

Sleeman R, van Eck T (1999) Robust automatic P-phase picking: an on-line implementation in the analysis of broad band seismogram recordings. Phys Earth Planet Inter 113:265-275

Spallarossa D, Ferretti G, Augliera P, Bindi D, Cattaneo M (2001) Reliability of earthquake location procedures in heterogeneous areas: synthetic tests in the south western Alps, Italy. Phys Earth Planet Inter 123:247-266

Tarantola A, Vallette B (1982) Inverse problems = quest for information. J Geophys 50:159-170

Tarvainen M (1992) Automatic seismogram analysis: statistical phase picking and locating methods using onestation three-component data. Bull Seismol Soc Am 82:860-869

Tong C (1995) Characterization of seismic phases-an automatic analyzer for seismograms. Geophys J Int 123:937-947. doi:10.1111/j.1365-246X.1995.tb06900.x

Tong C, Kennett BLN (1996) Automatic seismic event recognition and later phase identification for broad band seismograms. Bull Seismol Soc Am 86:1896-1909

Wagner GS, Owens TJ (1996) Signal detection using multichannel seismic data. Bull Seismol Soc Am 86:221-231

Wessel P, Smith WHF (1991) Free software helps map and display data. Eos Trans AGU 72:441, 445-446. doi:10.1029/90EO00319

Wittlinger G, Herquel G, Nakache T (1993) Earthquake location in strongly heterogeneous media. Geophys J Int 115:759-777. doi:10.1111/j.1365-246X. 1993.tb01491.x

Zhang H, Thurber C, Rowe C (2003) Automatic Pwave arrival detection and picking with multiscale wavelet analysis for single-component recordings. Bull Seismol Soc Am 93(5):1904-1912. doi:10.1785/ 0120020241

Zhou H (1994) Rapid 3-D hypocentral determination using a master station method. J Geophys Res 99:15,43915,455 